\title{
"A gente dá um jeito!"”: percepções do setor de recepção sobre a língua inglesa em hotéis de grande porte em Florianópolis
}

"We find a way!": perceptions of the reception sector on the english language in large hotels in Florianópolis

“Nosotros lo arreglamos!": percepciones del sector de recepción sobre el idioma inglés en hoteles de gran tamaño en Florianópolis

http://dx.doi.org/10.18472/cvt.18n1.2018.1380

Luciane Lanznaster 〈lucianelanznaster@hotmail.com > Instituto Federal de Santa Catarina (IFSC), Florianópolis, SC, Brasil

Marimar da Silva 〈marimar.silva@ifsc.edu.br >

Instituto Federal de Santa Catarina (IFSC), Florianópolis, SC, Brasil

1 Fala de um dos participantes da pesquisa ao ser perguntado como se comunica com um turista estrangeiro em inglês ao recebê-lo no hotel.

CRONOLOGIA DO PROCESSO EDITORIAL

Recebimento do artigo: 18-dez-2016

Aceite: 08 -jan-2018

FORMATO PARA CITAÇÃO DESTE ARTIGO

LANZNASTER, L.; SILVA, M. da. “A gente dá um jeito!” : percepções do setor de recepção sobre a língua inglesa em hotéis de grande porte em Florianópolis. Caderno Virtual de Turismo. Rio de Janeiro, v. 18, n. 1, p. 223-237, abr. 2018.

REALIZAÇÃO

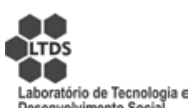

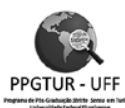

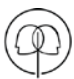

IABS
APOIO INSTITUCIONAL

COPPE

UFR]
EDIÇÃO

ERTORA

$=$
PATROCÍNIO

Universidade
Federal
Fluminense




\section{RESUMO}

Impulsionada pela evolução da tecnologia e pelo fenômeno da globalização, a indústria hoteleira vem se transformando para atender às necessidades de clientes estrangeiros que solicitam serviços cada vez mais exclusivos. Nesse cenário, ter competência comunicativa na língua inglesa tornou-se uma demanda profissional da hotelaria. Este estudo, de natureza qualitativa, investiga as percepções do setor de recepção sobre a língua inglesa em dois hotéis de grande porte em Florianópolis. Para tanto, foi coletado material documental, realizada entrevista semiestruturada e aplicado questionário a quatorze colaboradores do setor. A análise dos dados revelou que os participantes percebem a competência comunicativa na língua inglesa como uma ferramenta básica em sua rotina profissional. No entanto, apesar de ser uma demanda, a realidade ainda está aquém das necessidades do setor de recepção. O estudo ainda mostra uma lacuna na formação profissional específica em hotelaria e em língua inglesa entre os participantes da pesquisa, uma rotatividade significativa de profissionais no setor e sugere ampliar o escopo da investigação a fim de corroborar ou refutar os resultados obtidos.

Palavras-chave: Indústria Hoteleira. Língua Inglesa. Setor de recepção. Florianópolis/SC.

\section{ABSTRACT}

Driven by the evolution of technology and by the phenomenon of globalization, the hotel industry has been transformed to attend the needs of foreign guests, who request more and more exclusive services. In this scenario, holding communicative competence in English has become a professional demand for this industry. This study, qualitative in nature, investigates the perceptions of reception desk employees about the English language in two large hotels in Florianópolis. To do so, it was collected documental material, conducted a semi-structured interview and applied a questionnaire to fourteen professionals of the sector. Data analysis revealed that the participants perceive the communicative competence in English as a basic tool in their professional routine. However, despite being a demand, the reality is still below the ratio the reception sector needs. The study also revealed a gap in professional training in the hospitality area and in English, a significant professionals' turnover in the sector, and suggests broadening the scope of this research topic to corroborate or refute its results.

Keywords: Hotel Industry. English Language. Reception Sector. Florianópolis/SC.

\section{RESUMEN}

Impulsada por la evolución de la tecnología y por el fenómeno de la globalización, la industria hotelera se ha transformado con el fin de satisfacer las necesidades de los clientes extranjeros que solicitan servicios cada vez más exclusivos. En este escenario, tener competencia comunicativa en el idioma Inglés se ha convertido en una demanda profesional de la industria. Este estudio, de naturaleza cualitativa, investiga las percepciones de los empleados del sector de recepción sobre el idioma Inglés de dos hoteles de gran tamaño en Florianópolis. Por lo tanto, se recogió material documental, se realizó una entrevista semiestructurada y se aplicó un cuestionario a catorce trabajadores del sector. El análisis de los datos reveló que los participantes perciben la competencia comunicativa en el idioma Inglés como una herramienta básica en su rutina profesional. Sin embargo, a pesar de ser una demanda, la realidad está todavía abajo de las necesidades del sector de recepción. El estudio también reveló una brecha en la formación específica en hotelería y en el idioma Inglés entre los participantes, una rotación significativa de personal en el sector y sugiere ampliar el alcance de la investigación para confirmar o refutar los resultados obtenidos.

Palavras clave: Hotelería. Idioma Inglés. Sector de Recepción. Florianópolis/SC. 


\section{INTRODUÇÃO}

Na sociedade contemporânea, a indústria hoteleira encontra-se em grande transformação devido à evolução da tecnologia, da ciência e das estratégias de administração, que aperfeiçoam as empresas ante as necessidades dos clientes e as demandas de um mercado altamente competitivo (BLANCO; LEÃO; GUZZO, 2013).

Em se tratando de contemporaneidade e língua inglesa, Ortiz (2006) coloca que, apesar de a multiplicidade de idiomas circular normalmente na sociedade contemporânea, o fenômeno da globalização ${ }^{2}$ adotou a língua inglesa como ferramenta preferencial de comunicação ${ }^{3}$ entre povos de diferentes nações. Sobre esse fenômeno, Rajagopalan (2010) coloca que "[...] 'o inglês do mundo' ou 'o inglês mundial' [...] não tem dono [...] pertence a todos aqueles milhões de pessoas que dele fazem uso diário no mundo inteiro". (RAJAGOPALAN, 2010, p. 23). Assim, como língua mundial para a comunicação, a língua inglesa passa a ser (ou deveria, seguindo a tendência global) a ferramenta de acolhimento aos milhares de turistas estrangeiros que visitam nosso país.

Segundo Nascimento (2016), citando dados do Ministério do Turismo, dos 6.305.838 estrangeiros que visitaram o Brasil em 2015, 2.079.823 eram da Argentina, o que equivale a 33\% do total, os Estados Unidos mantiveram a segunda posição, com 575.796, seguido do Chile, com 306.331 turistas. No município de Florianópolis, o cenário não é diferente. Florianópolis é um dos responsáveis pelo movimento intenso de atrações e de turistas de diversos locais do Brasil e do mundo. A capital do estado de Santa Catarina está em terceiro lugar, abaixo somente do Rio de Janeiro e de Foz do Iguaçu, entre os lugares mais visitados pelo turista estrangeiro nos anos de 2010 e 2011, quando o motivo da viagem internacional é puramente lazer (FUNDAÇÃO INSTITUTO DE PESQUISAS ECONÔMICAS; MINISTÉRIO DO TURISMO, 2012).

Os dados estatísticos impressionam e colocam não apenas o Brasil, mas também o município de Florianópolis em foco, o que por si só já justificaria pesquisa na área de turismo. Uma rápida busca na base

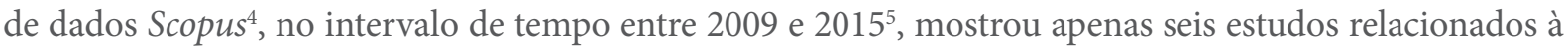
língua inglesa e hotelaria, mas nenhum deles no Brasil. Já no banco de teses e dissertações da Capes ${ }^{6}$, entre 2009 e 2015, cinquenta e seis estudos foram identificados, mas nenhum abordava o tema língua inglesa na hotelaria. Porém uma busca em Revistas de Turismo no Brasil mostrou três estudos: dois relacionados a línguas estrangeiras na hotelaria e um relacionado à operacionalização no setor de recepção hoteleiro, o que sugere uma lacuna na área.

Com base nessas evidências, este estudo busca investigar a percepção de colaboradores do setor de recepção em relação à língua inglesa no desenvolvimento de suas rotinas profissionais em hotéis de grande porte em Florianópolis-SC. A partir dessa compreensão, espera-se contribuir para a área de pesquisa e para o contexto investigado.

\footnotetext{
2 Estima-se que existem hoje em torno de 400 milhões de falantes nativos de inglês e que o número de falantes não nativos é três vezes maior. Fonte: https://en.wikipedia.org/wiki/English-speaking_world. Acesso em: 16 ago. 2016.

3 Os termos "comunicação" e "interação" são usados como sinônimos neste estudo.

4 Scopus é um dos maiores bancos de dados em publicações científicas nos campos da medicina, da tecnologia, das ciências sociais e humanas. Disponível em: 〈http://www.elsevier.com/solutions/scopus〉. Acesso em: 16 ago. 2016.

50 intervalo de tempo da busca realizada no Scopus (2009-2015) justifica-se pelo fato de o Brasil ter sediado a Copa Mundial de Futebol, em 2014, e os Jogos Olímpicos, em 2016, e de o governo brasileiro ter incentivado projetos para o ensino de línguas, visando melhor atender aos atletas e turistas internacionais que prestigiariam tais eventos.

6 Capes é o acrônimo para Coordenação de Aperfeiçoamento de Pessoal de Ensino Superior.
} 
O presente artigo está organizado em cinco seções. A primeira apresentou o cenário onde o estudo está inserido; a segunda apresenta o referencial teórico que deu apoio ao estudo; a terceira, o percurso metodológico; a quarta, a análise dos dados; e a quinta, a conclusão e considerações finais.

\section{REFERENCIAL TEÓRICO}

A demanda turística vem se modificando por conta do fenômeno da globalização, da evolução da economia, do progresso tecnológico, da exigência dos consumidores, entre outros fatores (BENI, 2006). Segundo o autor, as transformações que aconteceram no turismo nas últimas décadas estão fazendo com que empreendimentos turísticos busquem uma posição de maior qualidade no mercado, que pode ser alcançada por meio da elaboração de estratégias ou de vantagens competitivas.

Conforme Castelli (2007), essas estratégias ou vantagens podem estar associadas, por exemplo, a novos modos de organização e gestão, qualidade, flexibilidade e cuidado diferenciado com o consumidor. E acrescenta que a nova era do turismo se caracteriza por serviços turísticos pensados em consonância com as exigências particulares dos clientes, marketing direcionado para mercados exclusivos, viajantes com maior experiência e estímulo procurando por regiões que deem valor à cultura local, fazendo com que esta passe a integrar a vivência turística e as novas tecnologias de informação e comunicação, que possibilitam uma maior flexibilidade às companhias de turismo.

Essa nova visão de turismo, empresas e serviços turísticos também afetam a indústria hoteleira. Dias (2005) e Beni (2006) afirmam que, com o passar do tempo, o mercado hoteleiro sofreu alterações por conta da evolução na demanda turística, que passou a ser cada vez mais diferenciada e exigente. Para Beni (2006) e Castelli (2007), essas transformações fazem com que as companhias turísticas busquem uma posição de maior qualidade no setor hoteleiro, por meio da formulação de estratégias ou vantagens competitivas, as quais incluem também o acolhimento diferenciado do hóspede.

Nesse sentido, Castelli (1994) argumenta que hotéis são indústrias de serviços que proporcionam naturalmente o contato humano durante a ação de produtividade e obtenção do produto do hotel. Por sua vez, Ford, McNair e Perry (2005) alertam sobre a importância de se delimitar as expectativas dos clientes na área de serviços e enfatizam que "na qualidade de clientes espera-se: consideração e qualidade de serviço" (FORD et al., 2005, p. 101). Já Vallen e Vallen (2003) enfatizam que é necessário entender o que significa qualidade de serviço na perspectiva do cliente do setor hoteleiro. Para os autores:

\footnotetext{
Do ponto de vista do hóspede, a qualidade é o grau no qual uma propriedade oferece o que ele espera. Se surpreendê-lo com uma estada melhor do que a esperada, o hotel é visto como de alta qualidade, mas se a visita não atender às expectativas, a propriedade perde conceito. (VALLEN; VALLEN, 2003, p. 202)
}

Observa-se que o parâmetro para conceituar um estabelecimento hoteleiro como de qualidade na perspectiva do cliente está diretamente relacionado ao atendimento das expectativas deste; logo, um conceito altamente subjetivo. Nesse sentido, Poser (2005) alerta que no momento em que o hóspede busca um serviço, essa busca diz respeito a uma resposta para uma demanda. Por esse motivo, o fator emocional está diretamente associado ao consumo de serviços: "Não se adquire produtos e serviços. Adquirem-se soluções, e elas são altamente emocionais!” (POSER, 2005, p. 2). 
Assim, a sensibilidade para satisfazer um cliente com qualidade no setor hoteleiro está ligada não apenas às expectativas individuais de cada cliente, mas também à percepção de que cada cliente é exclusivo e, dessa forma, suas demandas tornam-se individualizadas. Poser (2005) ainda alerta que é necessário analisar a necessidade e o desejo do hóspede, não apenas oferecer o que se intui que ele quer.

Nessa perspectiva, as empresas, e aqui inclui-se a hotelaria, devem ser percebidas e funcionar como uma organização emocional, não apenas como um sistema organizacional monótono em termos de atuação e produtividade, se quiserem manter-se competitivas no mercado (DA SILVA; KNOLL, 2015). Dessa forma, saber se comunicar e estar em sintonia com o hóspede, visando a satisfazer suas expectativas com exclusividade, adquirem um alto grau de relevância no setor de recepção de um hotel.

No contexto hoteleiro de grande porte, saber se comunicar em diferentes idiomas, para atender ao hóspede com qualidade e exclusividade, tende a adquirir relevância ainda maior. Ter competência comunicativa na língua inglesa parece ser condição sine qua non para o setor de recepção hoteleiro trabalhar na busca da excelência e competitividade no mercado. Nesse contexto, atuar com colaboradores que têm competência comunicativa ${ }^{7}$ na língua inglesa pode ser uma estratégia ou vantagem competitiva (BENI, 2006; CASTELLI, 2007), uma vez que tende a facilitar a interação entre colaboradores e hóspedes estrangeiros, o acolhimento destes e, ainda, causar uma sensação de aproximação com a cultura do hóspede, em alguns casos, dando um toque de exclusividade ao atendimento.

Em estudo visando a identificar as principais necessidades dos colaboradores de hotéis de grande porte, mais especificamente recepcionistas, mensageiros e gestores, em relação ao uso da língua inglesa e às principais dificuldades linguísticas enfrentadas no exercício da sua função profissional, Silva e Bonifácio (2015) concluíram que entre as rotinas hoteleiras a língua inglesa precisa ser bastante utilizada em conversas espontâneas, em telefonemas, em e-mails e na tradução de cardápios de restaurantes, e constataram que o profissional hoteleiro formado na área e fluente em inglês ainda não é valorizado pela gestão dos grandes hotéis de João Pessoa, além de terem de disputar espaço no mercado de trabalho com profissionais sem qualificação e sem domínio do idioma.

Nessa mesma linha de investigação, o estudo de Blanco et al. (2013) sobre o setor de reservas em hotéis de Porto Alegre em relação ao grau de entendimento de reservas feitas em espanhol, inglês e português e de retorno ao cliente revelou um baixo índice de retorno dos e-mails, dificuldades gerais nos idiomas, no conteúdo das informações e na cordialidade das respostas, além do fato de muitos empreendimentos não darem retorno ao pedido do cliente.

Como sugerem os estudos de Silva e Bonifácio (2015) e de Blanco et al. (2013), a indústria hoteleira no Brasil necessita de investimento em larga escala no elemento humano para se alinhar às novas demandas do setor, que não são poucas ou simples.

No que tange à operacionalidade do hotel, Santos et al. (2010) argumentam que o setor de recepção hoteleiro é a parte nobre do hotel, pois é nesse ambiente que o hóspede - do check-in ao check-out obtém todas as informações sobre produtos e serviços oferecidos pelo estabelecimento, e enfatizam que o objetivo do setor é encantar o cliente para que este tenha uma imagem positiva do hotel.

7 Competência comunicativa é entendida aqui como “a habilidade de aplicar regras gramaticais da língua [inglesa] para formar enunciados gramaticalmente corretos e também saber quando e onde usá-las e com quem”. (RICHARDS; PLATT; PLATT, 1999, p. 65) 
Como parte de um sistema organizacional complexo, o setor de recepção de um hotel é constituído de um grupo de funcionários ${ }^{8}$ que desenvolvem rotinas e procedimentos, objetivando a satisfação do hóspede e a eficiência dos serviços, principalmente a rapidez dos procedimentos de check-in e checkout (DAVIES, 2003). Segundo o autor, as rotinas e os procedimentos do setor englobam: informar ao hóspede os serviços e produtos do hotel; fazer o check-in; responsabilizar-se pelo serviço de cofre; pela alteração de apartamento de forma ágil, quando necessário, e pelo fluxo de caixa; além de cuidar do livro de reclamações, observando críticas e sugestões; e de controlar o fluxo de saída no fim da estadia de cada cliente.

Conforme se observa, as rotinas e os procedimentos realizados no setor de recepção são mediados pela língua(gem), ou seja, da reserva ao check-out, há algum tipo de interação verbal ou escrita entre o colaborador do setor e o hóspede. No caso de um hotel de grande porte, onde a recepção de turistas estrangeiros acredita-se que seja mais frequente, há necessidade de os colaboradores realizarem os procedimentos do setor na língua inglesa, visando à agilidade dos serviços e à satisfação do cliente em sua experiência no hotel.

Para Kunsch (1997), a hotelaria do futuro terá de se responsabilizar por oferecer uma cultura organizacional que estreite os laços com o cliente, trabalhando com agilidade no processo inicial de abordagem para a conquista do hóspede. Nesse ponto, Ismail (2010) ressalta a importância de uma comunicação compreensível e precisa, a qual ultrapassa a verbal, englobando todo o relacionamento firmado durante a estadia e, na maioria dos casos, após o fechamento desta. Portanto, ter competência comunicativa em outros idiomas, como a língua inglesa, por exemplo, faz-se essencial para quem atua no setor hoteleiro, considerando que a interação (verbal ou escrita) ajuda a conhecer e a conquistar o cliente.

Em uma área na qual a competitividade é acirrada, o diferencial no atendimento é de suma relevância para atingir resultados que ultrapassem os dos concorrentes. Segundo Castelli (2007, p. 144), “[...] se todos os hotéis oferecem aproximadamente a mesma coisa, quem quiser se diferenciar deverá oferecer um serviço melhor ou diferente do que os demais, seus concorrentes". Ainda conforme Castelli (2007, p. 29):

As empresas prestadoras de serviço devem apostar fundamentalmente na qualidade do elemento humano, já que a excelência do serviço, condição da competitividade e sobrevivência da empresa, depende de como esse elemento humano está interagindo com os clientes. (CASTELLI, 2007, p. 29).

Assim, investir na qualificação do colaborador pode impactar positivamente a excelência do serviço prestado pelo hotel, que, por sua vez, pode vir a fidelizar o cliente e, como consequência, elevar o nível de competitividade da empresa em um processo cíclico, espiral e contínuo.

Para Castelli (2007), na gestão de serviços, o cliente é o maior patrimônio da organização. Uma empresa consegue atingir êxito sempre que produzir o que vende e, na circunstância de uma prestadora de serviços, o que ela vende são os desejos dos clientes. Por essa razão, o setor de recepção deve lidar de forma efetiva no atendimento dos desejos do cliente, de suas necessidades, expectativas, condutas e tendências.

Satisfazer as necessidades dos clientes tornou-se imprescindível para as organizações que buscam a qualidade total. Entretanto, atualmente é necessário ir além, é necessário encantar os hóspedes (CASTELLI,

\footnotetext{
8 Segundo Davies (2003), os cargos do setor englobam: o gerente de recepção, o supervisor de recepção, o assistente de gerente de recepção, o porteiro, o mensageiro, o telefonista, o encarregado de reservas, o gerente de reservas e o concierge, ressaltando aqui que o tamanho da equipe é proporcional à tipologia e à função social de cada hotel.
} 
2007). Nesse sentido, Lovelock e Wright (2004) argumentam que o cliente encantado tem maior tendência a manter-se fiel com relação às ofertas competitivas atraentes e, como resultado, completará a venda, consolidando a marca e a imagem da organização hoteleira. No entanto, alertam para o contrário em caso de desencantamento dos serviços prestados.

Entende-se aqui que atender ao hóspede com eficiência e eficácia demanda, entre outros fatores, uma interação adequada em idioma adequado. Atualmente, falar mais de um idioma com propriedade não é uma questão de encantar o cliente positivamente, mas uma demanda básica da indústria hoteleira. Hoje em dia, a competência comunicativa na língua inglesa é a ferramenta pela qual desejos e necessidades do cliente, associados à experiência da hospedagem, podem ser satisfeitos com eficiência e eficácia. Da mesma forma, a impossibilidade de interação adequada em idioma adequado com o hóspede pode resultar em desencantamento com a organização hoteleira e trazer impactos negativos, visto que a interação entre o colaborador e o hóspede faz parte da rotina e dos procedimentos básicos para o bem receber e o encantamento do cliente. A próxima seção descreve a metodologia do estudo.

\section{PROCEDIMENTOS METODOLÓGICOS}

Para a realização deste estudo, que visa responder à seguinte pergunta: Que percepções os colaboradores do setor de recepção de dois hotéis de grande porte em Florianópolis-SC têm em relação à língua inglesa no desenvolvimento dos procedimentos de atendimento ao turista estrangeiro?, utilizou-se a abordagem qualitativa.

A abordagem de pesquisa de natureza qualitativa preocupa-se "[...] com aspectos da realidade que não podem ser quantificados, centrando-se na compreensão e explicação da dinâmica das relações de um grupo [...]." (CÓRDOVA; SILVEIRA, 2009, p. 31).

Neste estudo, contou-se com as seguintes fontes de coleta de dados: (1) documentos do hotel; (2) questionário com perguntas abertas e fechadas; e (3) entrevista semiestruturada para guiar a conversa com os participantes, quatorze colaboradores do setor de recepção dos hotéis selecionados, a citar: seis recepcionistas, três mensageiros, dois concierges, dois gestores de recepção e um gestor de concierge.

No sentido de responder à pergunta guiadora deste estudo, a coleta de dados foi estruturada em quatro etapas: (1) escolha do contexto; (2) escolha dos instrumentos de coleta de dados; (3) procedimentos de coleta de dados; e (4) procedimentos de análise dos dados. Na primeira etapa foi feita a escolha dos hotéis para a realização da pesquisa, aqui nominados: Hotel A e Hotel $\mathrm{B}^{9}$, por questões éticas e para manter o anonimato dos participantes. Na segunda etapa foi feita a escolha dos instrumentos de coleta de dados que incluiu: análise de documentos, que compreendeu a leitura de textos teóricos e de artigos sobre o objeto do estudo, de registros de visitas técnicas, de históricos dos hotéis em sites de reserva e de folhetos informativos dos hotéis; entrevista semiestruturada para guiar a conversa com os participantes; e questionário com perguntas abertas e fechadas, que foi enviado a dois avaliadores externos no sentido de

9 A escolha do Hotel A e do Hotel B deu-se pelo fato de se denominarem do tipo Resort, de estarem localizados em praias preferidas por turistas internacionais e de terem sidos os únicos que aceitaram participar da pesquisa. 
validá-lo. Na terceira etapa foi feito contato pessoal com os hotéis, visando explicar o objetivo da pesquisa e solicitar permissão para entrevista e aplicação do questionário aos colaboradores do setor de recepção. Tanto o Hotel A quanto o Hotel B aceitaram a realização da pesquisa somente após a leitura e avaliação do questionário, que foi feita no início do segundo semestre de 2016. Finalmente, na quarta etapa foi realizada a análise dos dados das diferentes fontes.

A análise das respostas foi realizada com base na técnica de comparação entre os dados das diferentes fontes e por confronto teórico. Assim, foi possível identificar as percepções dos participantes sobre a língua inglesa no setor de recepção dos hotéis estudados, entre outras questões que emergiram do processo. A próxima seção apresenta a análise dos dados.

\section{ANÁLISE DOS DADOS}

Esta seção apresenta, primeiramente, o perfil dos hotéis e dos colaboradores do setor de recepção dos contextos investigados. Na sequência, apresenta e discute as percepções dos participantes em relação à língua inglesa no desenvolvimento de suas rotinas e procedimentos nos hotéis investigados.

O Quadro 1 apresenta o perfil dos hotéis estudados conforme o número de Unidades Habitacionais (UH), taxa de ocupação na alta temporada, origem dos hóspedes e motivação de viagem.

\section{Quadro 1 - Perfil dos hotéis}

\begin{tabular}{|l|l|l|l|l|l|}
\hline & UH & $\begin{array}{c}\text { Colaboradores } \\
\text { do setor de } \\
\text { recepção }\end{array}$ & $\begin{array}{c}\text { Taxa de } \\
\text { ocupação } \\
\text { no verão }\end{array}$ & Origem do hóspede estrangeiro & $\begin{array}{l}\text { Motivação da } \\
\text { viagem }\end{array}$ \\
\hline HOTEL A & 278 & 18 & $80 \%$ & $\begin{array}{l}\text { Europeus, norte-americanos e } \\
\text { canadenses }\end{array}$ & Lazer \\
\hline HOTEL B & 242 & 15 & $70 \%$ & $\begin{array}{l}\text { Europeus, norte-americanos e } \\
\text { argentinos }\end{array}$ & Lazer \\
\hline
\end{tabular}

Fonte: dados da pesquisa.

De acordo com o Quadro 1, os hotéis estudados apresentam aproximadamente o mesmo número de $\mathrm{UH}$ - diferença de apenas 36 apartamentos - e praticamente o mesmo número de colaboradores no setor de recepção em proporção ao número de UH. Os hóspedes estrangeiros, provenientes dos continentes europeu e norte-americano e da Argentina, buscam os hotéis para lazer e são responsáveis por 70\% (Hotel B) a $80 \%$ (Hotel A) da taxa de ocupação durante a alta temporada.

O Quadro 2 apresenta o perfil dos colaboradores do setor de recepção conforme sua função, tempo de serviço no hotel, competência comunicativa (CC) da língua inglesa (LI) e grau de escolaridade. 
Quadro 2 - Perfil dos colaboradores do setor de recepção

\begin{tabular}{|c|c|c|c|c|c|}
\hline & $\begin{array}{l}\text { Participantes da } \\
\text { pesquisa }\end{array}$ & $\begin{array}{l}\text { Função no setor de } \\
\text { recepção }\end{array}$ & $\begin{array}{l}\text { Tempo de } \\
\text { serviço }\end{array}$ & CC na LI & Escolaridade \\
\hline \multirow{7}{*}{$\begin{array}{l}\text { HOTEL } \\
\text { A }\end{array}$} & \multirow{7}{*}{7} & Mensageiro (M1) & $\begin{array}{l}1 \text { ano e } 6 \\
\text { meses }\end{array}$ & Não & Ensino médio \\
\hline & & Mensageiro $(\mathrm{M} 2)$ & 2 meses & Não & $\begin{array}{l}\text { Superior } \\
\text { incompleto }\end{array}$ \\
\hline & & Recepcionista (R1) & $\begin{array}{l}\text { Não } \\
\text { respondeu }\end{array}$ & Sim & $\begin{array}{l}\text { Não } \\
\text { respondeu }\end{array}$ \\
\hline & & Recepcionista (R2) & $\begin{array}{l}\text { Não } \\
\text { respondeu }\end{array}$ & Sim & $\begin{array}{l}\text { Superior } \\
\text { cursando }\end{array}$ \\
\hline & & $\begin{array}{l}\text { Coordenador de } \\
\text { recepção }\end{array}$ & 1 ano & Sim & $\begin{array}{l}\text { Superior } \\
\text { incompleto }\end{array}$ \\
\hline & & Concierge (C) & $\begin{array}{l}3 \text { anos e } 2 \\
\text { meses }\end{array}$ & Sim & $\begin{array}{l}\text { Superior em } \\
\text { Hotelaria }\end{array}$ \\
\hline & & $\begin{array}{l}\text { Coordenador de } \\
\text { concierge }\end{array}$ & 7 anos & Sim & $\begin{array}{l}\text { Superior } \\
\text { completo }\end{array}$ \\
\hline \multirow{7}{*}{$\begin{array}{l}\text { HOTEL } \\
\text { B }\end{array}$} & \multirow{7}{*}{7} & Mensageiro (M1) & 2 anos & Pouca & Ensino médio \\
\hline & & $\begin{array}{l}\text { Supervisor de } \\
\text { recepcionista (R1) }\end{array}$ & 8 anos & Sim & $\begin{array}{l}\text { Superior } \\
\text { completo }\end{array}$ \\
\hline & & Recepcionista (R2) & 10 meses & Não & Ensino médio \\
\hline & & Recepcionista (R3) & 9 meses & Sim & Ensino médio \\
\hline & & Recepcionista (R4) & 7 anos & Não & Ensino médio \\
\hline & & Recepcionista (R5) & 9 meses & Não & Ensino médio \\
\hline & & Concierge (C) & 3 anos & Sim & $\begin{array}{l}\text { Superior } \\
\text { completo }\end{array}$ \\
\hline
\end{tabular}

Fonte: dados da pesquisa.

Conforme o Quadro 2, entre os 14 participantes que responderam sobre o tempo de serviço nos hotéis investigados, quatro trabalham menos de um ano, cinco trabalham entre um e três anos e apenas três mais de cinco anos, o que sugere certo grau de rotatividade na contratação de colaboradores, especialmente entre os mensageiros e recepcionistas em ambos os hotéis.

Ainda entre os participantes, seis deles não têm competência comunicativa na língua inglesa: dois mensageiros do Hotel A e três recepcionistas, além do supervisor de recepção do Hotel B. Devido às funções que os participantes desempenham nos hotéis, tal fato pode impactar negativamente na qualidade do atendimento ao hóspede estrangeiro, principalmente no Hotel B, que possui apenas dois recepcionistas e um concierge com competência na língua inglesa e um mensageiro com pouca competência. Nesse sentido, investimento no elemento humano (aprendizado da língua inglesa) poderá agregar valor aos serviços prestados em ambos os hotéis (CASTELLI, 2007).

Além disso, verifica-se que, entre os que responderam sobre o nível de escolaridade, no Hotel A, a maioria dos participantes está cursando nível superior, mas não na área de hotelaria. Por outro lado, os dados obtidos do Hotel B mostram que a maioria dos participantes, com exceção do supervisor de recepção e do concierge, estudou somente até o Ensino Médio. Tais dados indicam que os colaboradores 
não têm formação profissional específica em hotelaria, salvo o concierge do Hotel $\mathrm{A}$, e apenas oito dos 14 participantes têm competência na língua inglesa, o que corrobora os achados do estudo de Silva e Bonifácio (2015).

Comparando-se os dados do Quadro 1 com os do Quadro 2, na alta temporada, caso não haja novas contratações, o Hotel A terá cinco colaboradores no setor de recepção com competência comunicativa na língua inglesa para atender aos hóspedes estrangeiros de $80 \%$ de suas $278 \mathrm{UH}$, o que equivale a 222,4 do total de hóspedes, considerando-se apenas um hóspede por UH. Em outras palavras, um colaborador terá de atender às necessidades de, no mínimo, 44,48 hóspedes com qualidade e exclusividade. No Hotel $\mathrm{B}$, a situação não parece ser diferente, já que terá quatro colaboradores com competência comunicativa para atender aos hóspedes estrangeiros de 70\% de suas $242 \mathrm{UH}$, o que equivale a 169,4 do total de hóspedes, considerando-se igualmente apenas um hóspede por UH, ou seja, no Hotel B haverá um colaborador para atender às necessidades de, no mínimo, 42,35 hóspedes com igual qualidade e exclusividade. Tais dados indicam um risco para empresas que buscam excelência nos serviços ou no encantamento do cliente para que este tenha uma imagem positiva do hotel (SANTOS et al., 2010).

Ao perguntar aos participantes se precisam usar a língua inglesa para desempenhar sua função no setor de recepção, todos, independentemente da função que ocupam ou do hotel em que trabalham, afirmam que precisam usar a língua inglesa para desempenhar suas funções em diversos procedimentos. Por exemplo, os recepcionistas, tanto do Hotel A quanto do Hotel B, precisam usar a língua no atendimento telefônico, nos procedimentos de check-in e check-out, para dar informações e sugestões de restaurantes e pontos turísticos, na resolução de problemas e, inclusive, no registro e acesso a informações no sistema eletrônico de gerenciamento do hotel. Os mensageiros do Hotel A e do Hotel B precisam usar a língua desde a chegada do hóspede, quando descarregam sua bagagem, até levá-lo à sua UH e apresentar os espaços do hotel. E os concierges, por sua vez, usam a língua inglesa em todas as funções e procedimentos, como aluguéis de veículos e lanchas, reservas para festas, restaurantes e serviços ligados ao hotel. Além disso, ressaltam que, como muitos termos na hotelaria são em inglês, compreender a língua facilita o atendimento ao hóspede em geral.

Em suma, parece ser consenso entre os participantes que as interações com o hóspede estrangeiro no setor de recepção demandam o uso da língua inglesa e todos - do mensageiro ao gestor - têm consciência da importância da língua inglesa nas diferentes rotinas do setor de recepção dos hotéis investigados.

Ao perguntar aos participantes se fizeram, estão fazendo ou gostariam de fazer algum curso de inglês, descobriu-se que dois participantes do Hotel A (M1 e M2) não têm tempo e renda para investir no aprendizado da língua inglesa, e apenas um participante do Hotel B (R5) não tem tempo e interesse na língua. Os demais participantes estudam ou já estudaram a língua em algum momento de suas vidas. Para os que usam a língua no contexto profissional, esse aprendizado deu-se de diferentes formas: por meio de cursos no próprio hotel, em institutos de idiomas no Brasil ou no exterior, em experiências em diferentes países de língua inglesa ou não, ou de forma autônoma em cursos on-line. Ainda, os participantes que moraram no exterior veem essa experiência como um aspecto positivo em seu aprendizado. Já os participantes que não falam inglês apontam a falta de tempo e o custo dos cursos de idiomas como fatores negativos ao aprendizado da língua, sugerindo que, se tivessem ambas as condições, fariam investimento no seu aprendizado.

Tal compreensão do uso e da necessidade do uso da língua inglesa na rotina profissional sugere um movimento de busca de aprimoramento continuado por parte dos participantes e/ou por pressão do 
mercado, que pode resultar, por sua vez, em impacto positivo na qualidade dos serviços prestados no acolhimento e na satisfação do hóspede, na imagem do hotel e da cidade onde os hotéis estão inseridos. Nesse sentido, investimento no ensino-aprendizagem da língua inglesa para os colaboradores por parte dos hotéis de grande porte poderá viabilizar um incremento na qualidade dos serviços prestados e se converter em dividendos para o contexto local (hotel) e o global (cidade, país), haja vista o número de turistas que visitam o Brasil e o município de Florianópolis reportado pela Fundação Instituto de Pesquisas Econômicas e Ministério do Turismo (2012).

Ao perguntar aos participantes se gostariam de dar alguma sugestão ou ideia sobre capacitação em língua inglesa para o setor de recepção, alguns ofereceram alternativas que podem ser colocadas em prática de imediato, como, por exemplo, disponibilizar um manual de check-in/out em inglês com as principais frases utilizadas no setor, ou receber noções básicas da língua para solucionar o problema da falta de competência em língua inglesa quando identificada no setor de recepção; outros sugeriram capacitação e treinamento.

De modo geral, no que se refere à capacitação em língua inglesa, não há apenas preocupação entre os participantes de desenvolverem a competência comunicativa na língua, mas estes também sugerem alternativas plausíveis para lidar com os desafios de bem receber no setor de recepção. Logo, concluise que há interesse e engajamento por parte dos colaboradores em desempenhar sua função de forma apropriada. Castelli (2007), nesse sentido, alerta sobre a importância de o colaborador estar engajado nos objetivos da empresa; foco e esforço profissional auxiliam o hotel a alcançar seu diferencial competitivo.

Ao perguntar aos participantes sobre os impactos, no setor de recepção, quando o funcionário (não) fala a língua inglesa ao atender o hóspede estrangeiro, estes entendem que não ter competência comunicativa na língua inglesa prejudica a comunicação entre o funcionário do hotel e o turista estrangeiro, causando impacto negativo nos serviços prestados pelo hotel. Para os participantes, não entender as solicitações do cliente ou não conseguir se fazer entender ou, ainda, ter dificuldades de dar informações pode frustrar o hóspede e ser motivo para que este não se sinta acolhido e não retorne ao hotel. Como afirmou R1/ Hotel B: "Por não falar, acabo por não conseguir me comunicar, entender e me fazer entender, deixando o hóspede muitas vezes frustrado. O atendimento é $100 \%$ quando se fala a língua de forma clara e objetiva." [Dados da entrevista, ago. 2016]. Por outro lado, os participantes entendem que, quando o colaborador tem competência comunicativa na língua inglesa, o impacto nos serviços prestados pelo hotel pode ser positivo e trazer ao hóspede a sensação de atendimento exclusivo e de excelência, fortalecendo a imagem da empresa. Tal fato corrobora as ideias de Lovelock e Wright (2004). Segundo os autores, o cliente bem recebido é mais propenso a manter-se fiel à empresa, completará a aquisição de bens e serviços oferecidos e indicará o hotel para outras pessoas, fortalecendo a marca e a imagem da empresa.

Ao perguntar aos participantes se saber se comunicar na língua inglesa no contexto de um hotel de grande porte é essencial ou irrelevante, todos os entrevistados consideram não apenas essencial saber se comunicar na língua inglesa no contexto de um hotel de grande porte, mas em todos os setores e, principalmente, no atendimento direto ao hóspede. Vale ressaltar, entretanto, que os participantes do estudo consideram essa situação (ter competência comunicativa na língua inglesa) ideal, mas a realidade do contexto parece ser outra. Como afirmou R1/Hotel B durante a entrevista: "O ideal seria que em todos os setores se falasse inglês, mas na nossa realidade, tendo um funcionário por turno que fale já auxilia e muito para qualidade no atendimento em geral". [Dados da entrevista, ago. 2016]. 
Ao perguntar aos participantes se a capacitação dos funcionários para usar a língua inglesa com propriedade seria algo inovador no setor em que trabalham, apenas M1 e R1/Hotel B consideraram essa ação inovadora; os demais consideraram uma ação necessária. Tal fato reforça que o conhecimento da língua inglesa é uma ferramenta básica, um requisito para o desenvolvimento das rotinas e dos procedimentos dos colaboradores do setor de recepção dos hotéis estudados. Destaca-se ainda que, enquanto um recepcionista afirma que tal capacitação já acontece: "Tivemos sorteio de bolsas de estudo para o CCAA" [R3/Hotel B: dados da entrevista, ago. 2016], outro lembra que o interesse deve partir também do funcionário em aprender uma nova língua e não somente da empresa: "Poucas empresas oferecem a oportunidade e em contrapartida também tem de haver interesse dos funcionários" [R1/Hotel B: dados da entrevista, ago. 2016].

Parece haver, nos contextos investigados, um equilíbrio de interesse entre os hotéis e os colaboradores para que estes se aperfeiçoem, e também uma compreensão de que a língua inglesa não é mais um diferencial para surpreender ou encantar os hóspedes, como Castelli (2007) e Lovelock e Wright (2004) poderiam sugerir aos serviços do setor de recepção, mas a compreensão de que a língua inglesa é uma ferramenta obrigatória para que os colaboradores do setor possam desenvolver suas rotinas profissionais com a qualidade que os hotéis de grande porte exigem e divulgam oferecer.

Ao perguntar aos participantes se se comunicam com os turistas estrangeiros em inglês, em espanhol, misturando os idiomas, ou por meio de gestos, os participantes afirmaram utilizar todas as ferramentas possíveis, dentro do conhecimento de cada um, para atender ao hóspede em inglês com excelência. As ferramentas vão desde o conhecimento nas línguas estrangeiras (inglês e espanhol), passando por gestos, tradutores eletrônicos até o jeitinho: "Normalmente há um colega que fala inglês; caso não haja, a gente dá um jeito". [R4/Hotel B: dados da entrevista, ago. 2016]. Embora as atitudes dos participantes sugiram interesse, iniciativa e criatividade na busca de solução para seus desafios profissionais, cabe lembrar que o "jeitinho", por não ser uma ação teoricamente informada, pode afetar negativamente a qualidade dos serviços prestados.

Por fim, em conversa com os gestores de recepção, estes informaram que consideram a comunicação com o hóspede parte importante da hospitalidade, inclusive consideram a competência comunicativa e o interesse na língua estrangeira requisitos para contratar novos colaboradores. Por fim, afirmaram que os hotéis têm uma estrutura adequada para receber o hóspede estrangeiro, como material impresso, locação de passeios e guia de restaurantes e bares, mas não mencionaram sobre a estrutura humana.

Acredita-se, com base em Kunsch (1997) e Ismael (2010), que material impresso pode auxiliar na prestação de serviços na alta temporada, mas não substituir o caráter interpessoal exclusivo e humano que a comunicação face a face pode suscitar. Os referidos autores ressaltam que o estreitamento de laços com o cliente e a forma de comunicação durante o relacionamento firmado na estadia e, na maioria dos casos, após o seu fechamento são vitais no setor hoteleiro quando se trata de qualidade e de exclusividade de atendimento para conquistar o cliente. A iniciativa de ter material impresso para informar o hóspede estrangeiro pode minimizar situações específicas de atendimento na alta temporada, mas não justificar o número reduzido de colaboradores do setor de recepção com competência comunicativa na língua inglesa, conforme indicado no Quadro 2. A próxima seção traz as conclusões e as considerações finais do estudo. 


\section{CONSIDERAÇÕES FINAIS}

Este estudo, que se propôs a investigar as percepções de colaboradores do setor de recepção sobre a língua inglesa em sua rotina profissional em hotel de grande porte em Florianópolis, revelou que os participantes: i) percebem a língua inglesa como uma ferramenta básica de trabalho, pois é por meio dela que se comunicam com o hóspede estrangeiro, desenvolvem suas rotinas e procedimentos e mantêm a qualidade dos serviços do setor; ii) reconhecem que falar a língua inglesa ajuda a resolver problemas rotineiros com mais eficácia e contribui para a imagem do hotel; iii) reconhecem também que nem todos têm competência na língua inglesa, mas fazem uso de diferentes ferramentas, de tradutores eletrônicos a jeitinho, para lidar com a tarefa de atender ao hóspede estrangeiro; iv) entendem a falta de tempo e condições financeiras como entraves para investir no aprendizado da língua inglesa, e sugerem treinamento in loco, aulas e viagens ao exterior como formas de capacitação na língua inglesa, além de manuais com procedimentos de check-in/out, para minimizar a falta de competência na língua; e v) informaram haver investimento, em certa medida, na capacitação e contratação de colaboradores que têm alguma competência comunicativa na língua inglesa; porém não consideram essa capacitação uma ação inovadora, mas um requisito devido à função que a língua desempenha nas atividades profissionais do setor e ao impacto que ela pode ter na imagem do hotel.

Este estudo também revelou que os mensageiros, apesar de serem os primeiros a terem contato com os hóspedes estrangeiros, de conduzi-los aos seus quartos e de darem informações gerais sobre o hotel, que são atribuições importantes dadas a eles para o acolhimento ao hóspede, por não terem competência comunicativa na língua inglesa, essas atribuições tendem a se transformar em rotinas e procedimentos silenciosos. Nesse sentido, o estudo aponta para a importância de se investir, inclusive, na capacitação desses profissionais.

Além disso, ao comparar o número de colaboradores com competência comunicativa na língua inglesa com a taxa de ocupação dos hotéis na alta temporada, os hotéis investigados terão dificuldades de manter um atendimento exclusivo e de qualidade ao hóspede estrangeiro, caso não haja contratação de novos funcionários com competência em inglês. De acordo com os dados, os hotéis terão um ou dois funcionários com competência em inglês por turno para atender a $80 \%$ de suas $278 \mathrm{UH}$ (Hotel A) e a 70\% de suas $242 \mathrm{UH}$ (Hotel B), que estarão ocupadas com hóspedes provenientes dos continentes europeu, norte-americano e da América Latina.

Ademais, ao se observar os dados do perfil dos colaboradores do setor de recepção temos que, no Hotel A, apesar de a maioria dos participantes estar cursando nível superior, estes não estão relacionados à hotelaria e, no Hotel B, a maioria dos participantes estudou somente até o Ensino Médio. Assim, pode-se inferir que os colaboradores não têm formação profissional em hotelaria e nem em língua inglesa, salvo exceções, corroborando os achados do estudo de Silva e Bonifácio (2015). Isso significa dizer que, em Florianópolis, o profissional hoteleiro formado na área e fluente em inglês também tem de disputar espaço no mercado de trabalho com profissionais sem qualificação e sem domínio do idioma.

Agora, ao se agregar a esse resultado o tempo de serviço dos participantes, salvo uma recepcionista (R3) do Hotel B, os concierges e os coordenadores de ambos os hotéis, que têm mais de três anos de serviço, os demais funcionários têm menos de um ano ou um pouco mais, verifica-se que há uma rotatividade significativa de funcionários no setor; uma evidência a mais para o estudo de Silva e Bonifácio (2015). Isso significa dizer que, em Florianópolis, o profissional hoteleiro também não é valorizado pela gestão dos hotéis de grande porte. 
Dessa forma, pode-se dizer que a rotatividade de funcionários agregada à falta de valorização e de qualificação profissional em hotelaria e em língua inglesa pode fragilizar o estreitamento de laços com os clientes (KUNSCH, 1997) e uma comunicação compreensível e precisa (ISMAIL, 2010) em inglês, gerar frustração e propaganda boca a boca negativa (LOVELOCK; WRIGHT, 2004) sobre a imagem do hotel, entre outras questões.

Conclui-se que, no setor de recepção dos dois hotéis investigados, a língua inglesa é percebida como uma ferramenta básica na rotina profissional dos colaboradores do setor, porém nem todos têm competência comunicativa na língua; logo, em se mantendo o mesmo número de funcionários com o mesmo nível de competência em inglês no setor, na alta temporada, em ambos os hotéis, a consideração, a qualidade e a exclusividade de serviços (FORD et al., 2005) que o cliente espera, e que os hotéis se propõem a oferecer, podem não ocorrer ou ocorrer de tal forma que o decepcione.

Este estudo, alinhado às ideias de Castelli (2007, p. 29), acredita que "as empresas prestadoras de serviço devem apostar [...] na qualidade do elemento humano, já que a excelência do serviço, condição da competitividade e sobrevivência da empresa, depende de como este elemento humano está interagindo com os clientes". O cuidado com o cliente passa pela qualificação e valorização do profissional; logo, investimento nos colaboradores em relação ao aprendizado da língua inglesa e à formação específica na área de atuação são requisitos profissionais, como afirmou um dos participantes (Concierge/Hotel B), não um diferencial para encantar o cliente (LOVELOCK; WRIGHT, 2004) no setor hoteleiro, como inicialmente se acreditava.

Por fim, a título de se corroborar ou refutar os achados deste estudo, sugere-se que seja ampliado o escopo de investigação para hotéis de padrão igual e/ou diferente dos investigados e/ou se observe os colaboradores em suas rotinas profissionais com o hóspede estrangeiro, visando identificar o nível de competência comunicativa dos colaboradores do setor e de suas necessidades linguísticas, com vistas à elaboração de cursos de inglês a distância ou presencial e/ou de oficinas de capacitação in loco com foco específico em inglês para a hotelaria.

\section{REFERÊNCIAS}

BENI, M. C. Política e Planejamento de Turismo no Brasil. São Paulo: Alef. 2006.

BLANCO, L. A. de O.; LEÃO, T. S.; GUZZO, R. F. Atendimento do setor de reservas em relação aos idiomas na rede hoteleira de Porto Alegre. Convibra 2013 - on-line conference, 2013. X Congresso On-line de Administração - 7 a 9 de novembro de 2013.

CASTELLI, G. Excelência em Hotelaria. São Paulo: Qualitymark, 1994.

Gestão Hoteleira. São Paulo: Saraiva, 2007.

CORDOBA, F. P.; SILVEIRA, D. T. A pesquisa científica. In: GERHARDT, T. E.; SILVEIRA, D. T. (Org.). Métodos de Pesquisa. UAB/UFRGS. Porto Alegre. Editora da UFRGS, 2009. 120 p.

DAVIES, C. A. Manual de Hospedagem: simplificando ações na hotelaria. 2. ed. Caxias do Sul: Educs, 2003. (Coleção Hotelaria). 
DIAS, R. Introdução ao Turismo. São Paulo: Atlas, 2005.

FORD, L.; MCNAIR, D.; PERRY, B. 0 excepcional atendimento ao cliente. São Paulo: Edicta, 2005.

FUNDAÇÃO INSTITUTO DE PESQUISAS ECONÔMICAS - MINISTÉRIO DO TURISMO. Caracterização e dimensionamento do turismo doméstico no Brasil - 2010/2011. São Paulo, 2012.

ISMAIL, A. Hospedagem: front office e governança. São Paulo: Cengage Learning, 2010.

KUNSCH, M. M. K. Comunicação organizacional: surgimento e evolução das práticas, conceitos e dimensões. São Paulo: USP, 1997.

LOVELOCK, C.; WRIGHT, L. Serviços: marketing e gestão. Porto Alegre: Saraiva, 2004.

NASCIMENTO, L. Mais de 6 milhões de estrangeiros visitaram o Brasil em 2015. Disponível em: <http://www.turismo.gov.br/\%C3\%BAltimas-not\%C3\%ADcias/6131-mais-de-6-milh\%C3\%B5es-deestrangeiros-visitaram-o-brasil-em-2015.htmlı. Acesso em: 27 abr. 2016.

ORTIZ, R. Mundialização: saberes e crenças. São Paulo: Brasiliense, 2006.

POSER, D. Marketing de relacionamento: maior lucratividade para empresas vencedoras. Barueri. SP: Manole, 2005.

RAJAGOPALAN, K. O lugar do inglês no mundo globalizado. In: SILVA, K. A. (Org.). Ensinar e Aprender Línguas na Contemporaneidade: linhas e entrelinhas. Pontes Editores. 2010. 311 p.

RICHARDS, J. C.; PLATT, J.; PLATT, H. Dictionary of Language Teaching \& Applied Linguistics. England: Longman, 1999.

SANTOS, R. A.; CHEHADE, M. B.; GUIMARÃES JÚNIOR, S. P. Hotelaria: a operacionalidade de um hotel com ênfase na recepção. Revista Científica Eletrônica de Turismo. São Paulo. v. 7, n. 12, s/p. jan. 2010.

SILVA, J. C.; BONIFÁCIO, C. A. M. Inglês para hotelaria: análise das necessidades de aprendizado dos profissionais em hotéis de grande porte de João Pessoa/PB. Revista Hospitalidade. São Paulo, v. 13, n. 1, p. 438-462, jun. 2015.

SILVA, M. da; KNOLL, L. M. G. O Pensamento Sistêmico na (Trans)Formação do Profissional de Secretariado em Empreendedor. In: MARTINS, C. B.; D’ELIA, B. (Org.). Modelos de Gestão no Contexto do Profissional de Secretariado. Florianópolis: Departamento de Ciências da Administração/UFSC, 2015. p. 184-213.

VALLEN, G. K.; VALLEN, J. J. Check-in, check-out: gestão e prestação de serviços em hotelaria. 6. ed. Porto Alegre: Bookman, 2003. 